\title{
Soil Conservation and Smallholder Farmer Productivity: An Analytical Approach
}

\author{
Paul Kwame Nkegbe ${ }^{1}$ \\ ${ }^{1}$ Department of Economics \& Entrepreneurship Development, Faculty of Integrated Development Studies, \\ University for Development Studies, Wa, Ghana \\ Correspondence: Paul Kwame Nkegbe, Department of Economics \& Entrepreneurship Development, Faculty of \\ Integrated Development Studies, University for Development Studies, P. O. Box 520, Wa, Ghana. E-mail: \\ npk004@yahoo.com or pnkegbe@uds.edu.gh
}

\author{
Received: October 17, 2012 Accepted: November 5, 2012 Online Published: March 13, 2013 \\ doi:10.5539/jms.v3n2p92 URL: http://dx.doi.org/10.5539/jms.v3n2p92
}

\begin{abstract}
This paper analytically examines the relationship between farm household adoption of soil and water conservation practices and productivity in developing countries. A basic microeconomic model of the farm household is adopted and modified to develop the argument. The model reveals the use of soil and water conservation practices positively affects farm household productivity. The paper, however, cautions that the problem of soil and water conservation practices adoption might be inherently dynamic as benefits to some of the practices implemented in the present may only be realised in future, thus, a dynamic approach should be more appropriate for empirical analysis.
\end{abstract}

Keywords: household model, conservation practices, smallholder productivity, transactions costs, developing countries

\section{Introduction}

Most developing countries still rely heavily on agriculture so that factors accounting for poor performance of the sector also contribute a great deal to reduced incomes and hence increased poverty levels. The effect of soil erosion on rural livelihoods is increasingly becoming known in developing countries (Grepperud, 1995). For example, in northern part of Ghana, widespread soil loss and erosion (IRG, 2005; MoFA, 2007) coupled with declining soil fertility (EPA, 2003) has led to both governmental and non-governmental organizations promoting the use of soil and water conservation practices aimed at minimizing the debilitating effects of resource deterioration on the economic activities of the people (Nkegbe, 2011).

A basic assumption underlying the interventions in developing countries, mostly the degraded areas, is that adoption of the practices will improve environmental conditions which will in turn result in increased production or output and productivity. But to what extent is this assumption true, and does resource conservation have any effect at all on productivity? The study thus aims at analytically answering the question of resource conservation effect on smallholder productivity.

Several authors (for example, Grepperud, 1995; McConnell, 1983; Burt, 1981) have considered the economics of soil conservation emphasizing that for policy to be effective it should distinguish between private and socially optimal paths of erosion. Less attention, however, has been given to the theoretical analysis of how adoption of soil conservation practices influences (or specifically, improves) farmer productivity.

The analytical model for this study is inspired, in part, by the work of Barbier (2010) which characterizes the complex nexus of poverty and deterioration in the quality of natural resources in developing countries. The author argues that rural poor are mostly located in fragile environments as a result of which their livelihood and natural resource use are intimately linked. He notes that the poverty-natural resource degradation nexus is influenced by an intricate bundle of choices available to the poor, which in the absence of factor markets, is affected by their access to natural resource endowments and employment elsewhere. He thus concludes that reducing world poverty requires reducing the number of assetless poor and those living on the fringes of the environment.

This current paper shows the possible impact on output, and hence productivity, of applying soil and water 
conservation practices on cultivated holdings, especially in developing countries.

The rest of the paper is organized as follows. Section 2 briefly reviews soil conservation practices in developing countries, the next section presents and discusses the conservation-productivity model followed by model analysis. Section 5 then presents the concluding remarks of the study.

\section{Soil and Water Conservation Practices}

This section motivates the way conservation practices are classified for incorporation into the model. Different conservation practices are employed depending on the nature of the problem on the plot, and also depending on the locality and/or region. But the conservation practices have certain common characteristics. Two of such common characteristics identified by Grepperud (1995) are that their implementation involves costs which vary according to the type of practice chosen, and that they are beneficial to the extent that they check erosion and improve soil productivity resulting in increased production per unit area.

Generally, conservation practices can be loosely classified into either promoting productivity or conserving resources (Ersado et al., 2004). In the context of developing countries some productivity promoting practices include use of improved crop varieties with irrigation and modern inputs (like fertilizers), composting, mulching among others while resource conserving practices include bunds (soil and stone), terraces, agroforestry methods, grass stripping and cover cropping.

While some methods such as grass stripping and use of bunds are considered traditional practices in certain areas, they have been introduced to and adopted by smallholder farmers in other areas. These practices mainly aim at reducing surface runoff thereby minimizing the effects of erosion. For some of the methods, part of the available cultivable land is used up thus reducing the total land area for cropping (Grepperud, 1995). For others, especially those that involve the construction of structures, the benefits are not realised immediately, but may be gradually realised over time.

\section{The Conservation-Productivity Model}

For areas that are degraded, farm households consider it expedient using practices that do not only slow down run-off, but also improve the fertility of the soil. Such households will therefore adopt soil and water conservation practices so as to optimize the use of the land. To understand the linkage between agricultural practices (such as soil and water conservation measures) and household productivity, Swinton and Quiroz (2003) propose a two-step process. The first step can be stated algebraically as:

$$
R_{i t}=R_{i t-1}+Q\left(X_{t-1}, A_{t-1}, Z_{t-1}\right)+\varepsilon_{i t}
$$

which states that the quality of a given natural resource $i$ (such as land resource) at time $t$ is dependent on its quality in the previous period as well as changes shaped by a vector of inputs $X_{t-1}$, soil and water conservation practices $\left(A_{t-1}\right)$ used as conditioned by fixed characteristics $\left(Z_{t-1}\right)$ and idiosyncratic effects $\left(\varepsilon_{i t}\right)$. Restating the equation in terms of change in the quality of natural resource by subtracting $R_{i t-1}$ from both sides gives:

$$
\Delta R_{i}=Q(X, A, Z)+e
$$

From equation (2), the input vector variable $X$ and the conservation measures or practices vector $A$ are the factors directly under the control of the decision maker. The second step involves the determination of the factors influencing the adoption of the identified conservation practices which is pursued here within the context of the household modelling framework.

The conservation-productivity model presented here derives from the basic agricultural household model by Singh et al. (1986), and its modifications in the literature on efficiency analysis (Chavas et al., 2005) and crop diversity analysis (Benin et al., 2006; van Dusen, 2006; van Dusen and Taylor, 2005). The household typically makes production, consumption and labour allocation decisions. It produces agricultural commodities using its inputs - endowed and purchased - for consumption or for sale to the markets in a specific time period. However, it faces resource and market constraints (de Janvry et al., 1991; Singh et al., 1986; Taylor and Adelman, 2003).

The household is assumed to maximize utility from a set of farm produced consumption goods $C_{f}$, a set of

market purchased consumption goods $C_{m}$ and leisure $l$. Again, if it is assumed household members make decisions under the idea of cooperative bargaining, then the utility of the household also depends on the 
preferences and other characteristics of the household members $\theta_{h h}$, reflecting their relative bargaining power. The utility function can thus be represented by $U\left(C_{f}, C_{m}, l ; \theta_{h h}\right)$ and assumed to be non-satiated and quasi-concave in the arguments, that is, $U_{i}^{\prime}>0, U_{i}^{\prime \prime}<0$ and $i=C_{f}, C_{m}$, $l$. In producing farm outputs $Q_{f}$ the household uses family labour $F$, hired labour $H$, purchased inputs $X$, and conservation practices or measures to minimize the degradation of land $A$ (Note 1 ) thereby enhancing its quality $R$. The household members all together also use $L$ labour on off-farm activities to generate off-farm income $N$ (Note 2). The technology set facing the household can then be stated as $Q=Q\left(X, F, H, A \mid R, L ; Q_{f}, N\right)$ implying that factors $(X, F, H, A \mid R, L)$ can be used to produce farm and off-farm outputs $\left(Q_{f}, N\right)$, with $Q_{i}^{\prime}>0, \quad Q_{i}^{\prime \prime}<0, \quad Q_{i j}^{\prime \prime}>0$, and $i=X, F, H, A, L, i \neq j$. Individuals in the household have total time $T$ available to each of them which is allocated between farm work, off-farm work and leisure, with the constraint being $F_{i}+L_{i}+l_{i}=T$ with $F>0, L \geq 0, l>0$ implying that optimal time allotted to off-farm work by household members may be zero, but positive for farm production activities and leisure. If market prices are denoted by $p_{f}, p_{m}, p_{x}$ and $w$ respectively for produced commodities, purchased goods, input and wage rate with market constraints (Note 3) on the production and/or consumption expressed as functions of exogenous market characteristics $\theta_{m c}$, the household model can be represented as:

$$
\begin{gathered}
\underset{C_{f}, C_{m}, l}{\operatorname{Max}} U\left(C_{f}, C_{m}, l ; \theta_{h h}\right) \\
\text { subject to } \\
Q=Q\left(X, F, H, A \mid R, L ; Q_{f}, N\right) \\
F_{i}+L_{i}=T-l_{i} \\
p_{m} C_{m}+C\left(Q_{f} ; \theta_{e x}\right)=p_{f}\left(Q_{f}-C_{f}\right)+w L+E \\
M_{i}\left(Q_{f}, C_{f} ; \theta_{m c}\right)=0
\end{gathered}
$$

where $M_{i}(\cdot)$ is the market constraint function, $C(\cdot)$ is the farm production cost function (including the cost of hired labour) with exogenous farm effects, $E$ is exogenous non-labour income such as remittances, pensions and other transfers. For a non-tradable good $Q_{f}-C_{f}=0$ and so what determines household choices is its internal valuation of the good called shadow price $\rho$, but for a tradable good for which there are market constraints the $M_{i}(\cdot)$ is binding so that the market characteristics $\theta_{m c}$ determine whether household faces transactions costs for the good. If $\lambda$ represents the shadow value of income, $\gamma$ a vector of shadow values on the market constraints for goods and $\mu$ a shadow value of household time, then the Lagrangian to this model is given by:

$$
\begin{aligned}
\ell= & U\left(C_{f}, C_{m}, l ; \theta_{h h}\right)+\lambda\left[\left(p_{f}\left(Q_{f}-C_{f}\right)+w L+E\right)-p_{m} C_{m}-C\left(Q_{f} ; \theta_{e x}\right)\right] \\
& +\gamma\left(C_{f}-Q_{f} ; \theta_{m c}\right)+\mu\left[\left(T-l_{i}\right)-\left(F_{i}+L_{i}\right)\right]
\end{aligned}
$$


The first order conditions are as follows:

For all consumed goods

$$
U_{C_{f}}^{\prime}=\lambda p_{f}-\gamma_{i}
$$

For all produced goods

$$
C_{Q_{f}}^{\prime}=p_{f}-\frac{\gamma_{i}}{\lambda}
$$

For all tradables

$$
p_{m}=p_{m}^{0} \text { and } \gamma_{i}=0
$$

with $p_{m}^{0}$ being an exogenous market price. From this, the first order condition with respect to labour sold is

and market purchased goods is

$$
\begin{gathered}
\lambda w-\mu \leq 0, \text { since } L \geq 0 \\
U_{C_{m}}^{\prime}=\lambda p_{m}
\end{gathered}
$$

For non-tradables

$$
p_{m}=\rho_{i} \text { and } Q_{f}-C_{f}=0
$$

where $\rho_{i}$, the unobserved shadow price for good $i$, is determined by the internal equilibrium of supply and demand for good $i$. In particular, leisure (demand for a non-tradable) and labour used on-farm are given, respectively, as:

$$
U_{l}^{\prime}=\mu \text { and } p_{f} Q_{f_{F}}^{\prime}=\frac{\mu}{\lambda}, \lambda, \mu>0
$$

From the first order conditions above, the optimal choices of household members' time allotted to farm work, wage work and leisure are derived from equations (11b) and (13). Combining these equations yields the condition:

$$
\frac{U_{l}^{\prime}}{\lambda}=p_{f} Q_{f_{F}^{\prime}}^{\prime}=\frac{\mu}{\lambda} \geq w
$$

The condition (14) above states that households will equate their marginal value of leisure with that of labour allotted to farm production activities, and this will be equal to or greater than the prevailing market wage; a situation which determines whether or not the household participates in off-farm work (see also Barbier, 2010; Jacoby, 1993). If the internal valuation of household labour exceeds the market wage the household will decline to participate in off-farm work (i.e., if $\frac{\mu}{\lambda}>w$ then $L^{*}=0$ ).

For conservation practices

$$
C_{Q_{f_{A}}^{\prime}}^{\prime}=\frac{Q_{f_{A}}^{\prime}\left[\lambda p_{f}-\gamma_{i}\right]}{\lambda}=p_{f} Q_{f_{A}}^{\prime}, \gamma_{i}=0
$$

Equation (15) holds whether a tradable or a non-tradable good is produced with the use of soil and water conservation practices. It states that the household adopts a conservation measure or practice up to the point where the marginal cost and marginal value products of adoption are equal.

Constraints (4) to (7) are binding when the household participates in off-farm labour market, and also faces transactions costs in any market, which is determined by the characteristics of the market $\theta_{m c}$. The general solution to the household maximization problem presented here yields a set of reduced form constrained-optima given below for production and consumption respectively as:

$$
\begin{aligned}
& Q_{f}=Q_{f}^{c}\left(p, A_{j}, \theta_{h h}, \theta_{e x}, \theta_{m c}\right) \\
& C_{m}=C_{m}^{c}\left(p, \mathrm{Y}^{0}, \theta_{h h}, \theta_{e x}, \theta_{m c}\right)
\end{aligned}
$$

These are reduced form functions of prices including wages, exogenous non-farm income comprising off-farm labour income as well as remittances and other transfers, and household, farm and market characteristics. 


\section{Analysis}

\subsection{Adoption Decisions of Smallholders}

Besides the set of reduced form constrained-optima for production and consumption given, the general solution to the household maximization problem will also yield an input demand equation for conservation practice $A_{j i}$, the specific practice $A_{j}$ linked to the quality of land in equations (1) and (2) and it is given as:

$$
A_{j i}=A_{j}^{c}\left(p, A_{j}, \theta_{h h}, \theta_{e x}, \theta_{m c}\right)
$$

The constrained optimal input demand function for conservation practice is also dependent on prices of output and wages, levels of conservation practices other than the specific practice, exogenous non-farm income and household farm and market characteristics. Equation (18) together with (16) and (17) will inform the choice of variables for estimation of empirical models of conservation adoption, as well as productivity models.

\subsection{Productivity and Adoption of Conservation Practices}

Following Barbier (2010), the relationship between adoption of conservation practices and smallholder farmer productivity can be delineated as follows. If $w_{r}$ is the wage rate that just ensures that the optimal hours of off-farm work by the household is zero, also called the reservation wage rate, then it can be represented by the following relation:

$$
w_{r} \equiv\left[\frac{U_{l}^{\prime}}{\lambda}=p_{f} Q_{f_{F}}^{\prime}\right]_{L^{*}=0} .
$$

From relations (14) and (19), it can be inferred that the household will engage in off-farm work only if the market wage exceeds the reservation wage (i.e. $L^{*}>0$ if $w>w_{r}$ ), but the household will not engage in off-farm work if the market wage is less than or equal to the reservation wage (i.e. $L^{*}=0$ if $w \leq w_{r}$ ). Another inference that can be drawn from the equations is that if the household engages in off-farm work, then the optimal allocation of labour to farm production and also to leisure is given by their respective values equated to the market wage (i.e. $p_{f} Q_{f_{F}}^{\prime}=w$ defines $F^{*}$ and $U_{l}^{\prime} / \lambda=w$ defines $l^{*}$ if $w>w_{r}$ ).

Relationships contained in the inferences above are shown in Fig. 1 (Note 4). The vertical axis of the diagram depicts the wages (both the market wage and the reservation wage), and the horizontal axis depicts household labour allocation to both farm production and off-farm production activities. From the diagram, the marginal value of labour, $p_{f} Q_{f_{F}}^{\prime}$, to the household when it is engaged in farm production activities given the quality, $R_{0}$, of its resource endowment (specifically, land) is downward sloping because of the decreasing marginal productivity of labour, and at the same time the marginal cost of its engagement in farm production in terms of leisure is upward sloping due to the decreasing marginal utility of leisure. The intersection of these two curves determines the reservation wage $w_{r}$ of the household as shown in relation (19). An implication from the inferences drawn earlier is that if the market wage is equal to the reservation wage, $w_{r}$, then from Fig. 1 the household will devote $F_{r}$ labour to farm work, will not engage in off-farm work (i.e. $L^{*}=0$ ) and leisure will be given by $T-F_{r}$. However, if the prevailing market wage is greater than the reservation wage, depicted by $w$ in Fig. 1, then the household will engage in off-farm work by reducing both leisure and labour allotted to farm work. It is shown in the figure that $F_{0}$ labour will be devoted to farm work, $L_{0}$ to off-farm work and leisure will become $T-F_{0}-L_{0}$. 


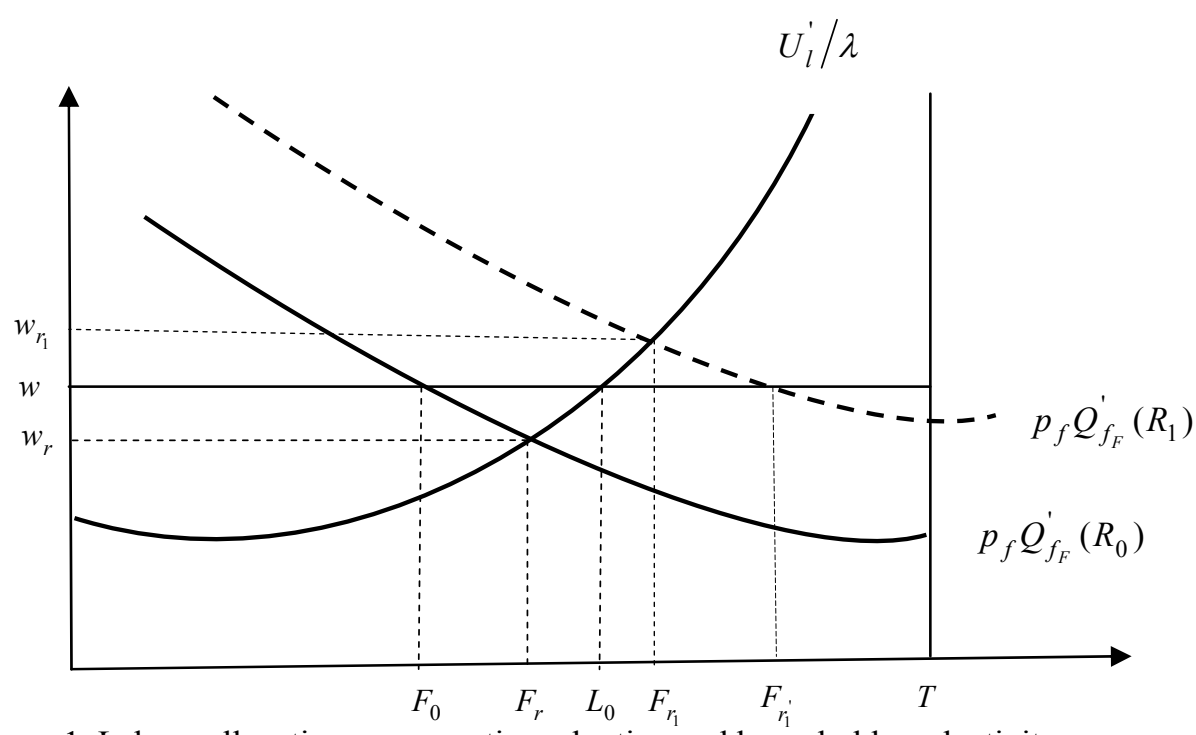

Figure 1. Labour allocation, conservation adoption and household productivity

It is the case that in developing countries where the fertility status of the soil is very low, the adoption of conservation practices will most likely enhance both the moisture status and the fertility of the soil. In general, thus, the quality of the land endowment available to the household will improve from $R_{0}$ to $R_{1}$ with the adoption of soil and water conservation practices. As shown in Fig. 1, the effect of this is that household labour productivity in farm production activities will surge as well as its reservation wage. If the market wage remains at $w$ the household will not devote any labour to off-farm work (i.e. $L^{*}=0$ since $w<w_{r_{1}}$ ), will increase the amount of labour devoted to farm production, $F_{r_{1}^{\prime}}$, while reducing leisure to $T-F_{r_{1}}$.

From the above discussion, it is clear that adoption of soil and water conservation practices will enhance land quality which results in moving the productivity curve from a lower level to an upper level. This thus leads to increased productivity of all inputs of production thereby increasing productivity of farm households as their level of production moves closer to the production frontier.

It is noted that the problem of soil and water conservation practices investigated in this study may be inherently dynamic as payoffs to some of the practices may be distant in time, implying a dynamic model should be more appropriate than the static model employed here since an optimal decision in the short-term may involve 'mining' the soil without undertaking any conservation investments. But the aim of the current study, which is to analytically show how conservation affects productivity, should still be achieved whatever approach is used. It can also be argued that given developing countries are the most degraded, further 'mining' of the soil might not be a feasible strategy, even if optimal in the short-term. Against this background, the use of the static model should still yield reasonably relevant and reliable conclusions.

\section{Concluding Remarks}

Principally, the paper reveals analytically that adoption of soil and water conservation practices in developing countries has positive effects on smallholder farm household productivity, and herein lies the contribution of this study. It also guides the choice of variables for empirical estimation of adoption of conservation practices and smallholder farmer production function. The model incorporates and acknowledges the important role imperfections in the capital and credit markets play in affecting the adoption of sustainable practices and hence productivity of farm households thereby highlighting the findings by some authors (e.g., Adesina and Djato, 1996; Chavas et al., 2005; Ray and Bhadra, 1993) in developing countries' context.

To empirically implement the analytical model in this study, the fact remains that cross-sectional data will only give information on technology use by a number of smallholders at some date, implying that the use of such data will not allow for exploring the adoption process itself (Besley and Case, 1993). A better strategy will thus involve using time-series or panel data (Note 5).

\section{Acknowledgements}

The author is indebted to Bhavani Shankar for his insightful comments in the preparation of the work which 
produced this paper. That notwithstanding, the usual disclaimer applies.

\section{References}

Adesina, A. A., \& Djato, K. K. (1996). Farm size, relative efficiency and agrarian policy in Côte d'Ivoire: profit function analysis of rice farms. Agricultural Economics, 14(2), 93-102. http://dx.doi.org/10.1016/0169-5150(96)01181-4

Barbier, E. B. (2010). Poverty, development, and environment. Environment and Development Economics, 15(Special Issue 06), 635-660. http://dx.doi.org/10.1017/S1355770X1000032X

Benin, S., Smale, M., \& Pender, J. (2006). Explaining the diversity of cereal crops and varieties grown on household farms in the highlands of northern Ethiopia. In M. Smale (Ed.), Valuing Crop Biodiversity: On-farm Genetic Resources and Economic Change (pp. 78-96). Oxfordshire: CABI Publishing.

Besley, T., \& Case, A. (1993). Modeling technology adoption in developing countries. American Economic Review, 83(2), 396.

Burt, O. R. (1981). Farm level economics of soil conservation in the Palouse area of the Northwest. American Journal of Agricultural Economics, 63(1), 83-92. http://dx.doi.org/10.2307/1239814

Chavas, J. P., Petrie, R., \& Roth, M. (2005). Farm household production efficiency: evidence from The Gambia. American Journal of Agricultural Economics, 87(1), 160-179. http://dx.doi.org/10.1111/j.0002-9092.2005

de Janvry, A., Fafchamps, M., \& Sadoulet, E. (1991). Peasant household behaviour with missing markets: some paradoxes explained. The Economic Journal, 101(409), 1400-1417. http://dx.doi.org/10.2307/2234892

EPA. (2003). National Action Programme to Combat Drought and Desertification. Accra: Environmental Protection Agency.

Ersado, L., Amacher, G., \& Alwang, J. (2004). Productivity and land enhancing technologies in northern Ethiopia: health, public investments, and sequential adoption. American Journal of Agricultural Economics, 86(2), 321-331. http://dx.doi.org/10.1111/j.0092-5853.2004.00581.x

Grepperud, S. (1995). Soil conservation and governmental policies in tropical areas: does aid worsen the incentives for arresting erosion? Agricultural Economics, 12(2), 129-140. http://dx.doi.org/10.1016/0169-5150(95)01139-C

IRG. (2005). Progress against Desertification: Case Studies of Experience in Ghana. International Resources Group, USAID.

Jacoby, H. G. (1993). Shadow wages and peasant family labour supply: an econometric application to the Peruvian Sierra. Review of Economic Studies, 60(4), 903-921. http://dx.doi.org/10.2307/2298105

McConnell, K. E. (1983). An economic model of soil conservation. American Journal of Agricultural Economics, 65(1), 83-89. http://dx.doi.org/10.2307/1240340

MoFA. (2007). Food and Agriculture Sector Development Policy (FASDEP II). Accra, Ghana: Ministry of Food and Agriculture, Republic of Ghana.

Nkegbe, P. K. (2011). Resource Conservation Practices: Adoption and Productive Efficiency among Smallholders in Northern Ghana. Unpublished PhD Thesis. University of Reading, Reading.

Ray, S. C., \& Bhadra, D. (1993). Nonparametric tests of cost minimizing behavior: a study of Indian farms. American Journal of Agricultural Economics, 75(4), 990-999. http://dx.doi.org/10.2307/1243986

Singh, I., Squire, L., \& Strauss, J. (Eds.). (1986). Agricultural Household Models: Extensions, Applications and Policy. Baltimore: Johns Hopkins University Press.

Swinton, S. M., \& Quiroz, R. (2003). Is poverty to blame for soil, pasture and forest degradation in Peru's Altiplano? World Development, 31(11), 1903-1919. http://dx.doi.org/10.1016/j.worlddev.2003.06.004

Taylor, J. E., \& Adelman, I. (2003). Agricultural household models: genesis, evolution and extensions. Review of Economics of the Household, 1(1-2), 33-58. http://dx.doi.org/10.1023/A:1021847430758

van Dusen, M. E. (2006). Missing markets, migration and crop biodiversity in the Milpa system of Mexico: a household-farm model. In M. Smale (Ed.), Valuing Crop Biodiversity: On-farm Genetic Resources and Economic Change (pp. 63-77). Oxfordshire: CABI Publishing.

van Dusen, M. E., \& Taylor, J. E. (2005). Missing markets and crop diversity: evidence from Mexico. Environment and Development Economics, 10(4), 513-531. http://dx.doi.org/10.1017/S1355770X05002317 


\section{Notes}

Note 1. In not too fertile areas, such as pertains in most developing countries, the use of soil and water conservation practices can be seen as an input in agricultural production and the use of such practices can be said to be dependent on land quality thus $A \mid R$.

Note 2. $N=w L$.

Note 3. It is normally the case in developing countries that certain markets, mostly that for output, function effectively so that we are still able to get information on prices even in the presence of market imperfections.

Note 4. As noted by Barbier (2010, p.651), in drawing the diagram, it is assumed that marginal productivity of labour in farm production activities by the household tends to zero if labour allotted by the household to such activities approaches zero, and that marginal utility of leisure approaches infinity if leisure approaches zero.

Note 5. This, the author, hopes to pursue in a subsequent extension and refinement of the current analysis depending on the availability of relevant data. 